\title{
Gene expression profiling in the Cynomolgus macaque Macaca fascicularis shows variation within the normal birth range
}

\author{
Bright Starling Emerald ${ }^{1,4^{*}}$, Keefe Chng ${ }^{1}$, Shinya Masuda ${ }^{1}$, Deborah M Sloboda ${ }^{2}$, Mark H Vickers ${ }^{2}$, Ravi Kambadur ${ }^{1,3}$ \\ and Peter D Gluckman ${ }^{1,2}$
}

\begin{abstract}
Background: Although an adverse early-life environment has been linked to an increased risk of developing the metabolic syndrome, the molecular mechanisms underlying altered disease susceptibility as well as their relevance to humans are largely unknown. Importantly, emerging evidence suggests that these effects operate within the normal range of birth weights and involve mechanisms of developmental palsticity rather than pathology.

Method: To explore this further, we utilised a non-human primate model Macaca fascicularis (Cynomolgus macaque) which shares with humans the same progressive history of the metabolic syndrome. Using microarray we compared tissues from neonates in the average birth weight $\left(50-75^{\text {th }}\right.$ centile) to those of lower birth weight (5$25^{\text {th }}$ centile) and studied the effect of different growth trajectories within the normal range on gene expression levels in the umbilical cord, neonatal liver and skeletal muscle.

Results: We identified 1973 genes which were differentially expressed in the three tissue types between average and low birth weight animals $(P<0.05)$. Gene ontology analysis identified that these genes were involved in metabolic processes including cellular lipid metabolism, cellular biosynthesis, cellular macromolecule synthesis, cellular nitrogen metabolism, cellular carbohydrate metabolism, cellular catabolism, nucleotide and nucleic acid metabolism, regulation of molecular functions, biological adhesion and development.
\end{abstract}

Conclusion: These differences in gene expression levels between animals in the upper and lower percentiles of the normal birth weight range may point towards early life metabolic adaptations that in later life result in differences in disease risk.

\section{Background}

Clinical, experimental and epidemiological studies have highlighted a link between the early-life environment and the health and well-being of offspring in later life. An adverse maternal environment has been linked to an increased risk of developing metabolic and cardiovascular disorders including type 2 diabetes, obesity, hyperlipidemia, insulin resistance and hypertension [1-7]. An important feature of these studies is that these relationships exist within the normative birth range and do not depend on extremes of birth weight. This has led to the

\footnotetext{
* Correspondence: bsemerald@uaeu.ac.ae

'Growth, Development and Metabolism Programme, Singapore Institute for Clinical Sciences, Brenner Centre for Molecular Medicine, 30 Medical Drive, Singapore

Full list of author information is available at the end of the article
}

proposal that later life disease risk is the result of maladaptive consequences of plastic mechanisms which would normally be adaptive $[8,9]$.

It is proposed that developmental plasticity determines the trajectory of development through epigenetic processes such that the fetus attempts to match its later phenotype to the environment [10]. It has been proposed that low birth weight is a marker of a poor early life nutritional environment [11] and thus a smaller fetus is more likely to develop a metabolic capacity appropriate for a low nutrient postnatal environment. But, if faced with a high nutrient environment it is more likely to become obese and insulin resistant [12]. Although, epigenetic processes have been increasingly implicated largely from rodent studies involving

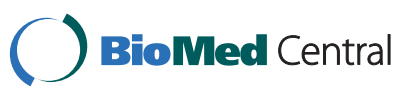

(C) 2011 Emerald et al; licensee BioMed Central Ltd. This is an Open Access article distributed under the terms of the Creative Commons Attribution License (http://creativecommons.org/licenses/by/2.0), which permits unrestricted use, distribution, and reproduction in any medium, provided the original work is properly cited. 
nutritional manipulation of the dam $[13,14]$ the molecular mechanisms underlying altered disease susceptibility are largely unknown. There is also some evidence that these developmental trajectories, and associated longterm gene expression and epigenetic changes can be reversed by the administration of the adipokine leptin to the neonatal rat although the concentrations used were higher than physiological levels $[10,12,15,16]$. These data suggest that a better understanding of the molecular events associated with impaired early life development may help in designing future intervention strategies.

To identify the possible molecular pathways associated with variations in the fetal environment, we have utilised a non-human primate (NHP) model, the Macaca fascicularis (Cynomolgus macaque) to elucidate whether variations within the normal birth weight range are associated with differential gene expressions patterns. Cynomolgus macaques share with humans the same progressive history of the metabolic syndrome [17] which makes this model directly relevant to humans and importantly, Cynomolgus macaque is a monotocous species in which spontaneous variation in fetal growth rather than experimental manipulation can be investigated. This study therefore we have investigated the effect of spontaneous lower birth weight on gene expression in key tissues (umbilical cord, hepatic tissue and skeletal muscle) from female Cynomolgus macaque neonates.

\section{Methods}

\section{Collection of Umblical cords}

Sixty-five pregnant Cynomolgus macaque dams, sired naturally by one male, were monitored prior to delivery at the Vietnam Primate Breeding and Development Corporation. After birth, dams were sedated (ketamine- $\mathrm{HCl}$; $7 \mathrm{mg} / \mathrm{kg}$ ) to facilitate collection of the umbilical cord. The cords were collected and immediately snap-frozen in liquid nitrogen and stored at $-80^{\circ} \mathrm{C}$ for later analyses. Neonates were weighed at birth and promptly returned to the dams. All animal procedures were approved by Nafovanny, subsidiary of the Ministry of Forestry, Vietnam, and performed in accordance with the guidelines set by the national advisory committee for laboratory animal research (NACLAR) of Singapore.

\section{Collection of hepatic and skeletal muscle samples}

The normative birth range was assessed from these 65 pregnancies and 8 neonates were selected based on their birth weights to comprise 2 groups: 1) lower birth weight group $(\boldsymbol{L B W}) ; \mathrm{n}=4$ classified as those that were within the $5^{\text {th }}$ to $25^{\text {th }}$ birth weight percentile, birth weight range 299-317 g and 2) average birth weight group $(A B W) ; \mathrm{n}=4$ classified as those that were within the $50^{\text {th }}$ to $75^{\text {th }}$ birth weight percentile, birth weight range 358-398 g. The normal gestation of Cynomolgus macaque is approximately $155-170$ days [18]. We have estimated the gestational age based on early ultrasound measurements (greatest length of the embryo at the time of pregnancy detection) and used those pregnancies where fetuses were within normal distribution for full term Cynomolgus macaques [18]. On postnatal day 5 , neonates were sedated with an intramuscular injection of ketamine- $\mathrm{HCl}(15 \mathrm{mg} / \mathrm{kg})$, and exsanguinated under anesthesia. Liver and skeletal muscle (biceps femoris) were collected and immediately snap frozen in liquid nitrogen and stored at $-80^{\circ} \mathrm{C}$ for later analyses

\section{Preparation of Total RNA}

Total RNA was isolated from umbilical cords and neonatal tissues using TRIzol reagent according to the manufacturer's instructions (Invitrogen). RNA integrity was confirmed by bio analyzer 2100 (Agilent Technologies, Santa Clara, USA). An RNA Integrity Number (RIN) value of 7.5 above was considered acceptable and used in further experiments.

\section{Microarray analysis}

For microarray analysis, RNA from 6 groups of samples (Cord: ABW and LBW; Liver: ABW and LBW; skeletal muscle: ABW and LBW) were labeled using QuickAmp 1-color labeling kit (Agilent Technologies) according to manufacturer's protocol. The Cy3 labeled cRNA were subsequently hybridized to Agilent Rhesus Macaque (G2519F-015421) Gene Expression microarray. The Rhesus macaque gene expression microarray used in this study represented 43,803 Rhesus monkey probes synthesized as 60-mers spotted using the Agilent SurePrint technology (Agilent Technologies). The microarrays were scanned with Agilent High resolution Scanner and the images were feature extracted using FE software version 10.5 (Agilent Technologies).

Data analysis was performed using Genespring GX ver10 (Agilent Technologies). The raw signal intensity from each samples is global normalized to 75 th percentile and base-line transformed. Probes flagged with present call in at least $75 \%$ of the samples in any of the 6 groups were used for subsequent data analysis.

Two-way ANOVA was performed with p value cut-off at 0.05 to identify genes that are differentially expressed in the tissue type and birth weight. Due to limited annotation of Rhesus Monkey genome, the microarray probes are annotated against human genes and ontology. For mapping against the human genome, the probes from the monkey microarray were re-annotated using Agilent eARRAY. The probe sequences were aligned to human genome (hg18) using BLAST based algorithm and the associated human annotation was extracted from the database. 
To study the gene expression profile of the birth weight in each of the tissue type, Welch T-Test with pvalue cut off of 0.05 and fold change of $1.5 \mathrm{X}$ was performed between the ABW and LBW samples in each of the tissue groups.

Complete microarray data is available at the Gene Expression Omnibus (GEO) database under the accession number GSE32069.

\section{Network Analysis}

The microarray data was imported into Pathway Studio version 7 (Ariadne Genomics, Rockville, USA) for network analysis. Gene Set Enrichment Analysis (GSEA) was performed on $\mathrm{ABW}$ vs $\mathrm{LBW}$ in the respective tissue using Kolmogorov-Smirnov algorithm with p-value cutoff at 0.05. In addition, Network Enrichment Analysis (NEA) was performed to identify expression hub of the treatment. Sub network was generated by connecting entities to their expression target network using the Resnet 7 Mammalian database.

\section{Quantitative RT-PCR}

Five up-regulated and two down regulated genes were selected for verification using qRT-PCR. The primers were designed using the Cynomolgus if available or Rhesus macaque sequences using the primer 3 software if not available [19]. The gene symbols and the primers are listed in Table 1.

We used skeletal muscle RNA to verify the array. Briefly, total RNA was extracted as mentioned above from four ABW and four LBW neonates and were reverse transcribed using Applied Biosystem's high-capacity cDNA reverse transcription kit using $1 \mu \mathrm{g}$ of total RNA in a reaction volume of $20 \mu \mathrm{l}$. The PCR reactions were carried out in $25 \mu \mathrm{l}$ of SYBR Green Master Mix with 200 ng of cDNA using 7500 real time PCR system (Applied Biosystems, CA, USA). The comparative Ct method was used to calculate the relative gene expression [20]. 18S RNA was used as the internal control which was validated using the method described in Schmittgen and Livak [20] and found to be stable and consistent.

\section{Results}

\section{Microarray analysis}

Two-way factorial ANOVA identified 1973 genes which were differentially expressed in the three tissue types between $\mathrm{ABW}$ and $\mathrm{LBW}$ neonates $(\mathrm{P}<0.05)$. Of these, 1141 genes were up regulated in the LBW samples while 832 genes were down-regulated in the LBW samples compared to ABW (Figure 1).

Gene expression profiles of umbilical cord, liver and skeletal muscle were also compared using Welch-t-test. There were 250 genes significantly and differently
Table 1 Sequences of primers used for qRT-PCR:

\begin{tabular}{l}
\hline PASK F 5' CTACTCCGGGAGCTGCTATC 3' \\
\hline PASK R5' AGCAGCAGAACAGAGGTGTG 3' \\
\hline 116936 F5' GCACATCTGCCTGAAGTGAA 3' \\
\hline 116936 R5' GAGCAGCTTGTCCAGGAAGT 3' \\
\hline ADK F5' TGGTGGCTCTACCCAGAACT 3' \\
\hline ADK R5' CATCTACATGGGCTTCAGCA 3'
\end{tabular}

ELMO F5' AGCTCTGTGTGGCTTGGTTT 3'

ELMO R5' CGGTGTGAATAACGGAGTCCT 3'

SIX1 F5' GTTTAAGAACCGGAGGCAAA 3'

SIX1 R5' GGAGAGAGTTGGTTCTGCTTG 3'

SLC12A9 F5' GGCTTCAACAGCAGTACCCT 3'

SLC12A9 R5' AAGAGGACAGCAAAGACGCT 3'

RBL1 F5' TAGCCTGACCAACATGGAGA 3'

RBL1 R5' GTTCAAGCAATTCTGCCTCA 3'

Uni18SrRNA F5' AGTCCCTGCCCTITGTACACA 3'

Uni18SrRNA R5' GATCCGAGGGCCTCACTAAAC 3

expressed in the liver, 850 genes significantly and differently expressed in the skeletal muscle and 891 genes significantly and differently expressed in cord samples $(\mathrm{P}<$ $0.05,>1.5$ fold difference) (Figure 2, 3). The top 50 genes whose gene expression levels changed in each tissue based on their fold difference based on Welch Ttest are given in Tables 2, 3, 4 .

Of the 250 genes which were differently expressed in the liver, 182 genes were unique to the liver (115 genes up regulated in the LBW group and 67 genes downregulated in the LBW group). There were 19 genes which were significantly and differently expressed between liver and skeletal muscle (16 up regulated in LBW skeletal muscle and 15 genes up regulated in liver and 3 down-regulated in the LBW skeletal muscle and 4 down regulated in LBW liver). There were 5 genes which are significantly and differently expressed between liver and cord ( 3 up regulated in LBW liver and 2 genes up regulated in LBW cord and 2 down regulated in LBW liver and 3 down regulated in the cord).

Of the 850 genes significantly and differently expressed in skeletal muscle, 733 genes were specific to the skeletal muscle; i.e. showed altered regulation only in the skeletal muscle (584 genes up regulated in the LBW samples and 149 genes down regulated in the LBW group). There were 94 genes which were 

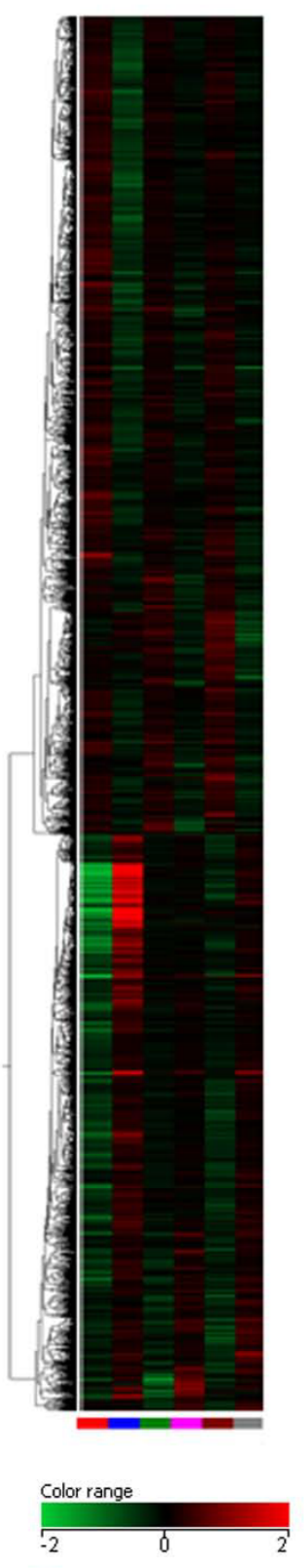

- B- ABW

- B- LBW

- $\mathrm{C}-\mathrm{ABW}$

- C- LBW

- L- ABW

- L- LBW

Figure 1 Hierarchical clustergram of 1973 genes (1141 up regulated in LBW and 832 down regulated in LBW) identified by ANOVA $(P<0.05)$ in all the three tissues (umbilical cord $(C)$, liver (L) and skeletal muscle (B) analyzed. The relative expression is reflected by the intensity of the color (Green $=$ down regulated, red $=$ up regulated)

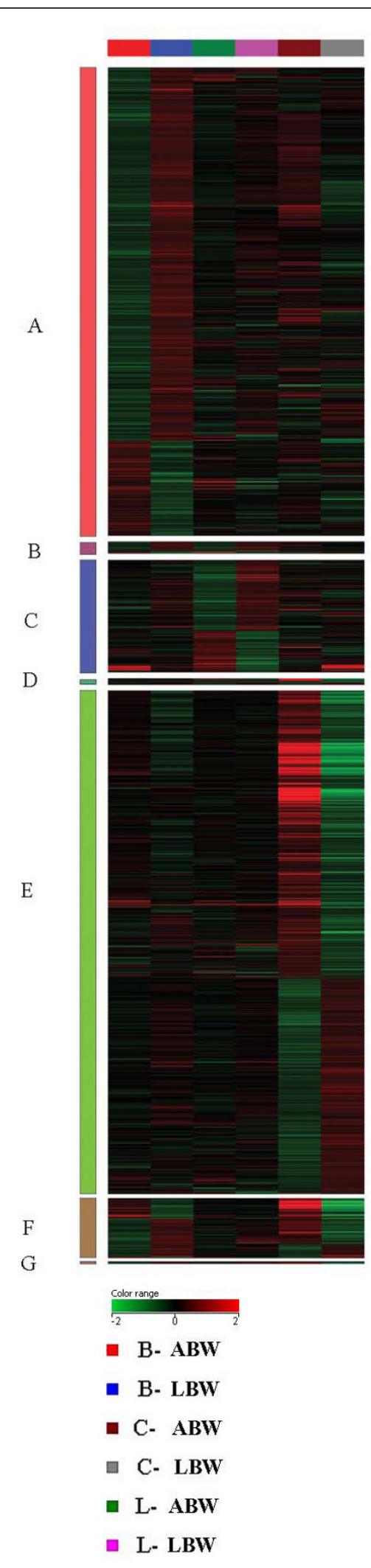

Figure 2 Heat map depicting the differentially expressed genes in skeletal muscle ( 850 genes), liver (210 genes) and 
cord (891 genes) $(\mathrm{P}<\mathbf{0 . 0 5},>=1.5$ fold difference). $\mathrm{A} .733$ genes (584 genes up regulated in LBW skeletal muscle, 149 genes down regulated in LBW skeletal muscle), B. 19 genes (16 genes up regulated in LBW skeletal muscle and 15 genes up regulated in LBW liver, 3 genes down regulated in LBW skeletal muscle and 4 genes down regulated in liver). C 182 genes (115 genes up regulated in LBW liver and 67 genes down regulated in LBW liver). D 5 genes (2 genes up regulated in LBW cords and 3 genes up regulated LBW liver, 3 genes down regulated in LBW cords and 2 genes down regulated in LBW liver). E. 788 genes (338 genes up regulated in LBW cord and 450 genes down regulated LBW cord). F. 94 genes (60 genes up regulated in LBW skeletal muscle and 22 up regulated in LBW cord, 34 genes down regulated in LBW skeletal muscle and 72 genes down regulated in LBW cord. G. 4 genes (4 genes up regulated in LBW skeletal muscle and liver, 4 genes down regulated in LBW cord).

significantly and differently expressed between skeletal muscle and cord (60 up regulated in LBW skeletal muscle and 22 genes up regulated in LBW cord and 34 genes down regulated in the LBW skeletal muscle and 72 genes down regulated in the LBW cord).

Of the 891 genes significantly and differently expressed in umbilical cord; 788 genes showed altered regulation only in umbilical cord (338 genes up regulated and 450 genes down regulated in LBW group). There were 4 genes which are significantly and differently expressed between liver, skeletal muscle and umbilical cord (4 genes up regulated in the LBW skeletal muscle and liver while the same four genes were down regulated in LBW cord) Figure 2, 3.

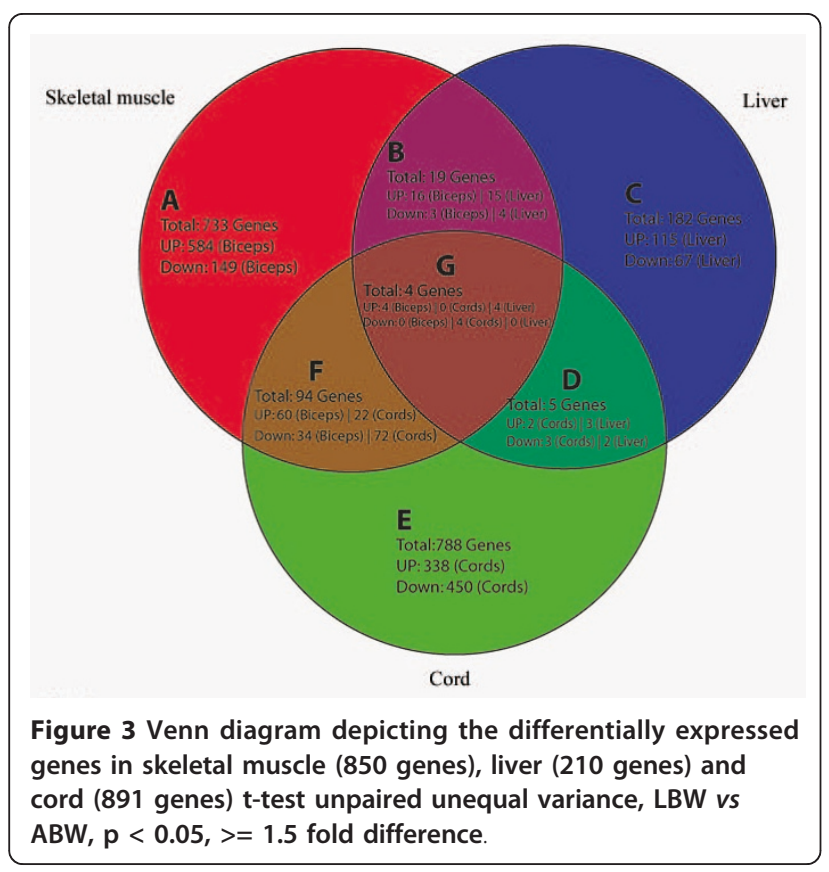

\section{Functional classification of genes}

Gene ontology was used to classify genes based on functional significance. The main component of the Gene Ontology (GO) annotation taken into consideration was metabolic function. Genes were classified into fifteen functional categories: Cellular lipid metabolic process (43 genes), Cellular biosynthetic process (95 genes), Cellular macromolecule synthesis (222 genes), Cellular nitrogen compound metabolic process (10 genes), Cellular carbohydrate metabolic process (6 genes), Cellular catabolic process (9 genes), Nucelobase, Nucleoside, nucleotide and nucleic acid metabolic process (216 genes), Other cellular metabolic process (29 genes), Other metabolic process (36 genes), Transport (141 genes), Regulation of molecular functions (28 genes), Biological adhesion (27 genes), Developmental process (74 genes) Other biological processes (252 genes) and Non classified (795) with p-value of $(p>0.05)$. The genes enriched for each $\mathrm{GO}$ term were further classified into the number of genes up regulated or down regulated in each tissue with a fold difference of 1.5 or greater (Table 5) (Additional file 1).

\section{Quantitative RT-PCR}

To validate the micoarray results we carried out quantitative RT-PCR (qRT-PCR) using the same RNA samples in the microarray analysis. We selected seven genes (a novel gene XM_116936, PAS domain containing serine/ threonine kinase (PASK), Adenisine kinase (ADK) transcript variant ADK-short, ELMO/CED-12 domain containing 1 (ELMOD1), Sine oculins homeobox homolog 1 (SIX1) Retinoblastoma like-1 (RBL1) and Solute carrier family 12 (potassium/chloride transporters) member 9 (SLC12A9) for this validation of the array using skeletal muscle cDNA. Of these 5 genes were significantly up regulated in the array and 2 genes were significantly down regulated in the array. Our results from the qPCR complement our results from the microarray (Table 6). The fold differences along with the values which derived from the microarray are presented in Table 6.

\section{Discussion}

In the present study, we have identified genes involved in key metabolic signaling pathways in three tissue types in a non-human primate model, that were differentially expressed according to the birth weight of the animal. Importantly, this differential expression was across the normal birth weight spectrum and therefore likely to represent adaptive pathways that the fetuses uses to predict its postnatal environment. The identification of novel signaling pathways that appear to be regulated by the early life environment is a key step in designing future experimental paradigms to understand the association between birth weight and disease risk. Metabolic 
Table $\mathbf{2}$ List of top $\mathbf{5 0}$ genes significantly differentially regulated in the skeletal muscle based on fold difference (t-test)

\begin{tabular}{|c|c|c|c|c|c|c|c|c|}
\hline Gene Symbol & $\begin{array}{l}2 \text { Way } \\
\text { ANOVA P } \\
\text { value }\end{array}$ & $\begin{array}{l}\text { Fold } \\
\text { Change in } \\
\text { Skeletal } \\
\text { muscle, } \\
\text { Welch t-test }\end{array}$ & $\begin{array}{l}\text { Regulation } \\
\text { in LBW }\end{array}$ & $\begin{array}{l}\text { Fold } \\
\text { change } \\
\text { Liver, } \\
\text { Welch } \\
\text { t-test }\end{array}$ & $\begin{array}{l}\text { Regulation } \\
\text { in LBW }\end{array}$ & $\begin{array}{l}\text { Fold } \\
\text { change } \\
\text { in Cords, } \\
\text { Welch } \\
\text { t-test }\end{array}$ & $\begin{array}{l}\text { Regulation } \\
\text { in LBW }\end{array}$ & Gene name \\
\hline XM_116936 & 0.017913306 & 10.054285 & up & 1.080386 & up & 2.185324 & up & $\begin{array}{l}\text { PREDICTED: Homo sapiens similar to } \\
\text { RIKEN CDNA 4832428D23 gene } \\
\text { (LOC196541) mRNA [XM_116936] }\end{array}$ \\
\hline XM_056254 & 0.021895792 & 9.569201 & up & 2.09208 & down & 1.391897 & up & $\begin{array}{l}\text { PREDICTED: Homo sapiens heparan } \\
\text { sulfate (glucosamine) 3-O- } \\
\text { sulfotransferase } 4 \text { (HS3ST4) mRNA } \\
\text { [XM_056254] }\end{array}$ \\
\hline C5orf23 & 0.01475329 & 6.0808635 & up & 1.072585 & up & 1.301361 & up & $\begin{array}{l}\text { Homo sapiens chromosome } 5 \text { open } \\
\text { reading frame } 23 \text { (C5orf23), mRNA } \\
\text { [NM_024563] }\end{array}$ \\
\hline$\overline{\text { PASK }}$ & 0.03426426 & 5.977056 & up & 2.995584 & up & 19.17474 & up & $\begin{array}{l}\text { Homo sapiens PAS domain } \\
\text { containing serine/threonine kinase } \\
\text { (PASK), mRNA [NM_015148] }\end{array}$ \\
\hline WDR8 & 0.004681234 & 5.6804295 & down & 2.978104 & down & 8.061375 & down & $\begin{array}{l}\text { Homo sapiens WD repeat domain } 8 \\
\text { (WDR8), mRNA [NM_017818] }\end{array}$ \\
\hline ADK & $1.63 \mathrm{E}-04$ & 5.639505 & down & 1.368648 & down & 9.386349 & down & $\begin{array}{l}\text { Homo sapiens adenosine kinase } \\
\text { (ADK), transcript variant ADK-short, } \\
\text { mRNA [NM_001123] }\end{array}$ \\
\hline APOBEC3G & 0.040698703 & 4.8567457 & down & 1.669566 & down & 1.105857 & down & $\begin{array}{l}\text { Homo sapiens apolipoprotein B } \\
\text { mRNA editing enzyme, catalytic } \\
\text { polypeptide-like 3G (APOBEC3G), } \\
\text { mRNA [NM_021822] }\end{array}$ \\
\hline$\overline{\mathrm{CCL} 2}$ & 0.002121243 & 4.757898 & down & 1.287543 & down & 2.895307 & down & $\begin{array}{l}\text { Homo sapiens chemokine (C-C motif) } \\
\text { ligand } 2 \text { (CCL2), mRNA [NM_002982] }\end{array}$ \\
\hline A_01_P013390 & 0.029869065 & 4.6248507 & down & 1.099004 & down & 1.527467 & down & \\
\hline BC044226 & 0.04677891 & 4.3998837 & down & 1.966762 & down & 1.502299 & down & $\begin{array}{l}\text { Homo sapiens myosin binding } \\
\text { protein } H, \text { mRNA [BC044226] }\end{array}$ \\
\hline CCL11 & 0.008992519 & 4.050988 & down & 3.178148 & down & 1.002582 & up & $\begin{array}{l}\text { Homo sapiens chemokine (C-C motif) } \\
\text { ligand } 11 \text { (CCL11), mRNA } \\
\text { [NM_002986] }\end{array}$ \\
\hline POU4F3 & 0.02459994 & 3.8642302 & up & 1.615214 & up & 1.991698 & down & $\begin{array}{l}\text { Homo sapiens POU domain, class 4, } \\
\text { transcription factor } 3 \text { (POU4F3), } \\
\text { mRNA [NM_002700] }\end{array}$ \\
\hline XR_011794 & 0.010519872 & 3.7855186 & up & 3.637105 & up & 2.76764 & up & $\begin{array}{l}\text { PREDICTED: Macaca mulatta similar to } \\
\text { poly(A)-specific ribonuclease (PARN)- } \\
\text { like domain containing } 1 \\
\text { (LOC707835), mRNA [XR_011794] }\end{array}$ \\
\hline $\mathrm{H1FOO}$ & 0.011109326 & 3.7804163 & up & 1.404401 & up & 1.449255 & down & $\begin{array}{l}\text { Homo sapiens H1 histone family, } \\
\text { member O, oocyte-specific (H1FOO), } \\
\text { mRNA [NM_153833] }\end{array}$ \\
\hline C17orf75 & 0.001362531 & 3.7583363 & down & 3.447702 & down & 1.443745 & down & $\begin{array}{l}\text { Homo sapiens chromosome } 17 \text { open } \\
\text { reading frame } 75 \text { (C17orf75), mRNA } \\
\text { [NM_022344] }\end{array}$ \\
\hline RNF216 & 0.001650785 & 3.7307158 & down & 1.504036 & down & 6.793567 & down & $\begin{array}{l}\text { Homo sapiens TRIAD3 protein } \\
\text { (TRIAD3), transcript variant 1, mRNA } \\
\text { [NM_207111] }\end{array}$ \\
\hline GTSF1 & 0.017040279 & 3.6632807 & up & 4.653995 & up & 2.487166 & up & $\begin{array}{l}\text { Homo sapiens family with sequence } \\
\text { similarity } 112 \text {, member B (FAM112B), } \\
\text { mRNA [NM_144594] }\end{array}$ \\
\hline C13orf33 & 0.006214988 & 3.5870998 & down & 2.664488 & down & 1.061963 & up & $\begin{array}{l}\text { Homo sapiens chromosome } 13 \text { open } \\
\text { reading frame } 33 \text { (C13orf33), mRNA } \\
\text { [NM_032849] }\end{array}$ \\
\hline CA2 & 0.033340864 & 3.5736616 & down & 3.483002 & down & 1.194329 & up & $\begin{array}{l}\text { Homo sapiens carbonic anhydrase ॥ } \\
\text { (CA2), mRNA [NM_000067] }\end{array}$ \\
\hline
\end{tabular}


Table 2 List of top $\mathbf{5 0}$ genes significantly differentially regulated in the skeletal muscle based on fold difference (t-test) (Continued)

\begin{tabular}{|c|c|c|c|c|c|c|c|c|}
\hline CO645773 & 0.03704907 & 3.5384166 & down & 2.022003 & down & 1.474969 & down & $\begin{array}{l}\text { ILLUMIGEN_MCQ_30118 Katze_MMPB } \\
\text { Macaca mulatta CDNA clone } \\
\text { IBIUW:22572 5' similar to Bases } 1 \text { to } \\
42 \text { highly similar to human RARRES3 } \\
\text { (Hs.17466), mRNA sequence } \\
\text { [CO645773] }\end{array}$ \\
\hline MYST3 & 0.013409907 & 3.3029778 & up & 2.827006 & up & 1.403819 & up & $\begin{array}{l}\text { Homo sapiens MYST histone } \\
\text { acetyltransferase (monocytic } \\
\text { leukemia) } 3 \text { (MYST3), mRNA } \\
\text { [NM_006766] }\end{array}$ \\
\hline NM_000977 & 0.008561992 & 3.2655115 & up & 2.138359 & up & 2.014805 & up & $\begin{array}{l}\text { Homo sapiens ribosomal protein L13 } \\
\text { (RPL13), transcript variant 1, mRNA. } \\
\text { [NM_000977] }\end{array}$ \\
\hline XR_014265 & 0.001382546 & 3.2319098 & down & 1.270026 & down & 2.168579 & down & $\begin{array}{l}\text { PREDICTED: Macaca mulatta } \\
\text { hypothetical protein LOC716045 } \\
\text { (LOC716045), mRNA [XR_014265] }\end{array}$ \\
\hline NM_001004685 & 0.043442905 & 3.1747854 & up & 1.353824 & up & 1.407273 & down & $\begin{array}{l}\text { Homo sapiens olfactory receptor, } \\
\text { family 2, subfamily F, member } 2 \\
\text { (OR2F2), mRNA. [NM_001004685] }\end{array}$ \\
\hline XR_014204 & 0.029225934 & 3.167453 & down & 3.849135 & down & 1.084816 & up & $\begin{array}{l}\text { PREDICTED: Macaca mulatta } \\
\text { hypothetical protein LOC719546 } \\
\text { (LOC719546), mRNA [XR_014204] }\end{array}$ \\
\hline DARS & 3.99E-05 & 3.1527941 & down & 1.10567 & down & 12.63266 & down & $\begin{array}{l}\text { Homo sapiens aspartyl-tRNA } \\
\text { synthetase (DARS), mRNA } \\
\text { [NM_001349] }\end{array}$ \\
\hline GYLTL1B & $9.45 \mathrm{E}-04$ & 3.143812 & up & 1.169517 & up & 3.19979 & up & $\begin{array}{l}\text { Homo sapiens glycosyltransferase-like } \\
\text { 1B (GYLTL1B), mRNA [NM_152312] }\end{array}$ \\
\hline CNNM2 & $1.94 \mathrm{E}-04$ & 3.1423542 & up & 1.00608 & down & 1.785853 & up & $\begin{array}{l}\text { Homo sapiens cyclin M2 (CNNM2), } \\
\text { transcript variant 1, mRNA } \\
\text { [NM_017649] }\end{array}$ \\
\hline C20orf26 & 0.023210809 & 3.1168563 & up & 1.353857 & up & 1.414684 & up & $\begin{array}{l}\text { Homo sapiens chromosome } 20 \text { open } \\
\text { reading frame } 26 \text { (C20orf26), mRNA } \\
\text { [NM_015585] }\end{array}$ \\
\hline SLC26A9 & 0.042099766 & 3.0884879 & up & 2.137558 & up & 1.776504 & up & $\begin{array}{l}\text { Homo sapiens solute carrier family } \\
\text { 26, member } 9 \text { (SLC26A9), transcript } \\
\text { variant 1, mRNA [NM_052934] }\end{array}$ \\
\hline SEC14L3 & 0.025527291 & 3.0402198 & up & 1.787294 & up & 1.547541 & down & $\begin{array}{l}\text { Homo sapiens SEC14-like } 3 \text { (S. } \\
\text { cerevisiae) (SEC14L3), mRNA } \\
\text { [NM_174975] }\end{array}$ \\
\hline TMEM20 & 0.001055841 & 2.9346027 & down & 1.821723 & down & 1.558415 & down & $\begin{array}{l}\text { Homo sapiens transmembrane } \\
\text { protein } 20 \text { (TMEM20), mRNA } \\
\text { [NM_153226] }\end{array}$ \\
\hline UHRF1 & 0.042854026 & 2.9323897 & down & 1.272487 & down & 1.455897 & down & $\begin{array}{l}\text { Homo sapiens ubiquitin-like, } \\
\text { containing PHD and RING finger } \\
\text { domains, } 1 \text { (UHRF1), transcript variant } \\
\text { 2, mRNA [NM_013282] }\end{array}$ \\
\hline CST9L & 0.008572864 & 2.9286344 & up & 1.46455 & up & 1.695363 & down & $\begin{array}{l}\text { Homo sapiens cystatin 9-like (mouse) } \\
\text { (CST9L), mRNA [NM_080610] }\end{array}$ \\
\hline C2 & 0.005425731 & 2.906241 & down & 1.470166 & down & 1.228973 & up & $\begin{array}{l}\text { Homo sapiens complement } \\
\text { component } 2 \text { (C2), mRNA } \\
\text { [NM_000063] }\end{array}$ \\
\hline C7orf62 & 0.03373279 & 2.8281868 & up & 1.466387 & up & 1.326441 & down & $\begin{array}{l}\text { Homo sapiens hypothetical protein } \\
\text { MGC26647 (MGC26647), mRNA } \\
\text { [NM_152706] }\end{array}$ \\
\hline HOXB13 & 0.008404698 & 2.822795 & up & 1.530259 & up & 1.061908 & down & $\begin{array}{l}\text { Homo sapiens homeobox B13 } \\
\text { (HOXB13), mRNA [NM_006361] }\end{array}$ \\
\hline ANLN & 0.026928915 & 2.8110342 & down & 1.205709 & down & 1.210447 & down & $\begin{array}{l}\text { Homo sapiens anillin, actin binding } \\
\text { protein (ANLN), mRNA [NM_018685] }\end{array}$ \\
\hline TMEM45B & 0.02836952 & 2.789488 & up & 1.108079 & up & 1.434473 & up & $\begin{array}{l}\text { Homo sapiens transmembrane } \\
\text { protein 45B (TMEM45B), mRNA } \\
\text { [NM_138788] }\end{array}$ \\
\hline
\end{tabular}


Table 2 List of top $\mathbf{5 0}$ genes significantly differentially regulated in the skeletal muscle based on fold difference (t-test) (Continued)

\begin{tabular}{|c|c|c|c|c|c|c|c|c|}
\hline COL8A2 & 0.029133584 & 2.7760508 & down & 1.111961 & down & 2.334076 & down & $\begin{array}{l}\text { Homo sapiens collagen, type VIII, } \\
\text { alpha } 2 \text { (COL8A2), mRNA } \\
\text { [NM_005202] }\end{array}$ \\
\hline IL15RA & $3.56 \mathrm{E}-05$ & 2.7710447 & down & 2.542192 & down & 5.776398 & down & $\begin{array}{l}\text { Homo sapiens interleukin } 15 \\
\text { receptor, alpha (IL15RA), transcript } \\
\text { variant 2, mRNA [NM_172200] }\end{array}$ \\
\hline AY937248 & 0.002621024 & 2.7557867 & up & 1.074139 & down & 2.046131 & up & $\begin{array}{l}\text { Macaca mulatta placental protein } 14 \\
\text { mRNA, complete cds [AY937248] }\end{array}$ \\
\hline SCN3B & 0.00199475 & 2.7342772 & up & 1.566765 & up & 1.26591 & up & $\begin{array}{l}\text { Homo sapiens sodium channel, } \\
\text { voltage-gated, type III, beta (SCN3B), } \\
\text { transcript variant 1, mRNA } \\
\text { [NM_018400] }\end{array}$ \\
\hline TRIM6 & 0.005424626 & 2.7181938 & up & 1.451755 & up & 1.960095 & up & $\begin{array}{l}\text { Homo sapiens tripartite motif- } \\
\text { containing } 6 \text { (TRIM6), transcript } \\
\text { variant 1, mRNA [NM_001003818] }\end{array}$ \\
\hline TNS4 & 0.041628703 & 2.7158492 & up & 1.315606 & up & 1.297834 & down & $\begin{array}{l}\text { Homo sapiens tensin } 4 \text { (TNS4), mRNA } \\
\text { [NM_032865] }\end{array}$ \\
\hline PDE1C & 0.026903268 & 2.6685586 & up & 1.596604 & up & 1.15087 & down & $\begin{array}{l}\text { Homo sapiens phosphodiesterase } 1 \mathrm{C} \text {, } \\
\text { calmodulin-dependent 70kDa } \\
\text { (PDE1C), mRNA [NM_005020] }\end{array}$ \\
\hline S100A4 & 0.01836204 & 2.656307 & down & 1.047433 & down & 2.01034 & down & $\begin{array}{l}\text { Homo sapiens } \$ 100 \text { calcium binding } \\
\text { protein A4 (S100A4), transcript variant } \\
\text { 1, mRNA [NM_002961] }\end{array}$ \\
\hline AADACL1 & 0.017924123 & 2.6216743 & down & 1.119603 & down & 1.47176 & down & $\begin{array}{l}\text { Homo sapiens arylacetamide } \\
\text { deacetylase-like } 1 \text { (AADACL1), mRNA } \\
\text { [NM_020792] }\end{array}$ \\
\hline XR_011345 & 0.029255124 & 2.6165082 & up & 1.450092 & up & 1.492756 & down & $\begin{array}{l}\text { PREDICTED: Macaca mulatta similar to } \\
\text { otoancorin isoform } 1 \text { (LOC699600), } \\
\text { mRNA [XR_011345] }\end{array}$ \\
\hline FN1 & 0.02028952 & 2.6025481 & down & 1.05622 & down & 1.051482 & down & $\begin{array}{l}\text { Homo sapiens fibronectin } 1 \text { (FN1), } \\
\text { transcript variant 1, mRNA } \\
\text { [NM_212482] }\end{array}$ \\
\hline SP7 & $3.05 E-04$ & 2.5985072 & up & 1.616763 & up & 1.088733 & down & $\begin{array}{l}\text { Homo sapiens Sp7 transcription } \\
\text { factor (SP7), mRNA [NM_152860] }\end{array}$ \\
\hline
\end{tabular}

disease particularly, has been strongly with early life adversity [21,22]. Our data begin to shed light on the key signaling pathways that are vulnerable to subtle changes in the early life environment.

The strength of our study, despite its small size, is that we have focused on infants whose growth was not experimentally manipulated but lay within normal birth weight range. Many experimental models have manipulated pregnancy in an effort to produce fetal growth restriction. Such studies have shown that offspring which are born growth restricted catch-up in growth with their normally nourished counterparts and in adulthood are obese, hypertensive, hyperinsulinemic, leptin resistant and display sedentary behavior [23-25]. Investigations into underlying mechanisms and the determination of gene expression levels that may explain these altered phenotypes have produced conflicting results [26-28] which may reflect variations in the model systems used and the gender of the animals used [28]. Taken together, although these studies have established the link between early life nutritional adversity to later pathophysiology, there are limitations in the interpretation of rodent studies in development as applied to humans.

In the present study we aimed to study the molecular associates of growth variation within the normative range and exclude pathology. This is because the growing literature on developmental outcomes highlights that the importance of variation in risk is associated with non-pathological developmental environments. Accordingly we studied relatively small infants born between the $5^{\text {th }}$ and $25^{\text {th }}$ centile but excluded the smallest neonates, which may reflect obstetrical abnormalities. These infants were compared to infants in the middle of the normative range $\left(50^{\text {th }}-75^{\text {th }}\right.$ centile) and accordingly we excluded infants who may have had macrosomia as a result of the mother's being over-nourished by being maintained in captivity. Thus we are confident that we have excluded pathological influences and demonstrated that within the normative range patterns of gene expression may vary considerably with variable birth weights. Indeed we found a number of genes with 
Table $\mathbf{3}$ List of top $\mathbf{5 0}$ genes significantly differentially regulated in liver based on fold difference (t-test).

\begin{tabular}{|c|c|c|c|c|c|c|c|c|}
\hline $\begin{array}{l}\text { Gene } \\
\text { Symbol }\end{array}$ & $\begin{array}{l}2 \text { Way } \\
\text { ANOVA P } \\
\text { value }\end{array}$ & $\begin{array}{l}\text { Fold } \\
\text { Change } \\
\text { in Liver } \\
\text { Welch } \\
\text { t-test }\end{array}$ & $\begin{array}{l}\text { Regulation } \\
\text { in LBW }\end{array}$ & 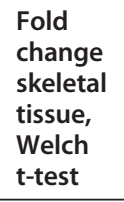 & $\begin{array}{l}\text { Regulation } \\
\text { in LBW }\end{array}$ & $\begin{array}{l}\text { Fold } \\
\text { change } \\
\text { in Cords, } \\
\text { Welch } \\
\text { t-test }\end{array}$ & $\begin{array}{l}\text { Regulation } \\
\text { in LBW }\end{array}$ & Gene name \\
\hline ELMOD1 & 0.011425177 & 25.931845 & down & 1.737314 & down & 2.051013 & up & $\begin{array}{l}\text { Homo sapiens ELMO/CED-12 domain } \\
\text { containing } 1 \text { (ELMOD1), mRNA } \\
\text { [NM_018712] }\end{array}$ \\
\hline RBBP9 & 0.026729036 & 11.012514 & down & 1.47388 & down & 5.131376 & down & $\begin{array}{l}\text { Homo sapiens retinoblastoma binding } \\
\text { protein } 9 \text { (RBBP9), mRNA [NM_006606] }\end{array}$ \\
\hline MMP25 & 0.001325307 & 10.996225 & down & 2.384582 & down & 1.436251 & down & $\begin{array}{l}\text { Homo sapiens matrix metallopeptidase } \\
25 \text { (MMP25), mRNA [NM_022468] }\end{array}$ \\
\hline C5orf46 & 0.047762383 & 10.762607 & down & 1.234639 & up & 1.096919 & up & $\begin{array}{l}\text { Homo sapiens similar to AVLV472 } \\
\text { (MGC23985), mRNA [NM_206966] }\end{array}$ \\
\hline GOLSYN & $2.29 \mathrm{E}-05$ & 6.13113 & up & 1.05566 & up & 1.458383 & up & $\begin{array}{l}\text { Homo sapiens hypothetical protein } \\
\text { FLJ20366 (FLJ20366), mRNA } \\
\text { [NM_017786] }\end{array}$ \\
\hline$\overline{\mathrm{LCN} 15}$ & 0.005291665 & 5.3478875 & up & 1.891747 & up & 2.217465 & up & $\begin{array}{l}\text { Homo sapiens MSFL2541 (UNQ2541), } \\
\text { mRNA [NM_203347] }\end{array}$ \\
\hline CCDC146 & 0.030661521 & 5.281487 & up & 1.06658 & up & 1.360575 & up & $\begin{array}{l}\text { Homo sapiens KIAA1505 protein } \\
\text { (KIAA1505), mRNA [NM_020879] }\end{array}$ \\
\hline AK094929 & 0.001118242 & 5.262121 & up & 1.690864 & up & 1.110624 & up & $\begin{array}{l}\text { Homo sapiens CDNA FLJ37610 fis, } \\
\text { clone BRCOC2011398. [AK094929] }\end{array}$ \\
\hline SORCS3 & 0.00328917 & 5.0026994 & up & 2.266284 & up & 2.921157 & up & $\begin{array}{l}\text { Homo sapiens sortilin-related VPS10 } \\
\text { domain containing receptor } 3 \\
\text { (SORCS3), mRNA [NM_014978] }\end{array}$ \\
\hline COL4A4 & 0.01571377 & 4.897748 & down & 1.548386 & down & 1.059327 & down & $\begin{array}{l}\text { Homo sapiens collagen, type IV, alpha } \\
4 \text { (COL4A4), mRNA [NM_000092] }\end{array}$ \\
\hline IL1R2 & 0.004347455 & 4.777918 & down & 1.8715 & down & 1.690538 & down & $\begin{array}{l}\text { Homo sapiens interleukin } 1 \text { receptor, } \\
\text { type II (IL1R2), transcript variant 1, } \\
\text { mRNA [NM_004633] }\end{array}$ \\
\hline$\overline{\text { CD200R1 }}$ & 0.04967409 & 4.7169123 & down & 1.052303 & up & 1.319852 & down & $\begin{array}{l}\text { Homo sapiens CD200 receptor } 1 \\
\text { (CD200R1), transcript variant 1, mRNA } \\
\text { [NM_138806] }\end{array}$ \\
\hline GTSF1 & 0.017040279 & 4.653995 & up & 3.663281 & up & 2.487166 & up & $\begin{array}{l}\text { Homo sapiens family with sequence } \\
\text { similarity 112, member B (FAM112B), } \\
\text { mRNA [NM_144594] }\end{array}$ \\
\hline SNAI1 & 0.005038617 & 4.582946 & down & 1.534132 & down & 1.847129 & down & $\begin{array}{l}\text { Homo sapiens snail homolog } 1 \\
\text { (Drosophila) (SNAI1), mRNA } \\
\text { [NM_005985] }\end{array}$ \\
\hline USH1C & 0.00505742 & 4.3276477 & up & 1.595945 & up & 1.465964 & up & $\begin{array}{l}\text { Homo sapiens Usher syndrome } 1 \mathrm{C} \\
\text { (autosomal recessive, severe) (USH1C), } \\
\text { transcript variant 1, mRNA } \\
\text { [NM_005709] }\end{array}$ \\
\hline ALLC & 0.006709512 & 4.060955 & up & 1.861818 & up & 2.766094 & up & $\begin{array}{l}\text { Homo sapiens allantoicase (ALLC), } \\
\text { transcript variant 1, mRNA } \\
\text { [NM_018436] }\end{array}$ \\
\hline $\mathrm{CXCL3}$ & 0.04903758 & 3.9091544 & down & 1.096309 & down & 1.172056 & up & $\begin{array}{l}\text { Homo sapiens chemokine (C-X-C motif) } \\
\text { ligand } 3 \text { (CXCL3), mRNA [NM_002090] }\end{array}$ \\
\hline XR_014204 & 0.029225934 & 3.8491352 & down & 3.167453 & down & 1.084816 & up & $\begin{array}{l}\text { PREDICTED: Macaca mulatta } \\
\text { hypothetical protein LOC719546 } \\
\text { (LOC719546), mRNA [XR_014204] }\end{array}$ \\
\hline XR_011794 & 0.010519872 & 3.637105 & up & 3.785519 & up & 2.76764 & up & $\begin{array}{l}\text { PREDICTED: Macaca mulatta similar to } \\
\text { poly(A)-specific ribonuclease (PARN)-like } \\
\text { domain containing } 1 \text { (LOC707835), } \\
\text { mRNA [XR_011794] }\end{array}$ \\
\hline$\overline{\text { NMNAT2 }}$ & 0.045685206 & 3.6255727 & up & 2.521069 & down & 2.189285 & up & $\begin{array}{l}\text { Homo sapiens nicotinamide nucleotide } \\
\text { adenylyltransferase } 2 \text { (NMNAT2), } \\
\text { transcript variant 1, mRNA } \\
\text { [NM_015039] }\end{array}$ \\
\hline
\end{tabular}


Table 3 List of top $\mathbf{5 0}$ genes significantly differentially regulated in liver based on fold difference (t-test). (Continued)

\begin{tabular}{|c|c|c|c|c|c|c|c|c|}
\hline SLC39A8 & 0.041505713 & 3.6139402 & down & 1.366996 & down & 1.390711 & down & $\begin{array}{l}\text { Homo sapiens solute carrier family } 39 \\
\text { (zinc transporter), member } 8 \text { (SLC39A8), } \\
\text { mRNA [NM_022154] }\end{array}$ \\
\hline CA2 & 0.033340864 & 3.4830022 & down & 3.573662 & down & 1.194329 & up & $\begin{array}{l}\text { Homo sapiens carbonic anhydrase II } \\
\text { (CA2), mRNA [NM_000067] }\end{array}$ \\
\hline NTRK3 & 0.003890598 & 3.4711208 & up & 1.593136 & up & 1.043792 & down & $\begin{array}{l}\text { Homo sapiens neurotrophic tyrosine } \\
\text { kinase, receptor, type } 3 \text { (NTRK3), } \\
\text { transcript variant 1, mRNA } \\
\text { [NM_001012338] }\end{array}$ \\
\hline C17orf75 & 0.001362531 & 3.4477015 & down & 3.758336 & down & 1.443745 & down & $\begin{array}{l}\text { Homo sapiens chromosome } 17 \text { open } \\
\text { reading frame } 75 \text { (C17orf75), mRNA } \\
\text { [NM_022344] }\end{array}$ \\
\hline CXCL1 & 0.006956845 & 3.392382 & down & 1.063934 & up & 4.611126 & down & $\begin{array}{l}\text { Homo sapiens chemokine (C-X-C motif) } \\
\text { ligand } 1 \text { (melanoma growth } \\
\text { stimulating activity, alpha) (CXCL1), } \\
\text { mRNA [NM_001511] }\end{array}$ \\
\hline NM_198692 & 0.03194352 & 3.3605232 & down & 1.343767 & up & 1.654617 & down & $\begin{array}{l}\text { Homo sapiens keratin associated } \\
\text { protein 10-11 (KRTAP10-11), mRNA. } \\
\text { [NM_198692] }\end{array}$ \\
\hline SHANK2 & 0.023280138 & 3.3547363 & up & 1.255762 & up & 1.189415 & down & $\begin{array}{l}\text { Homo sapiens } \mathrm{SH} 3 \text { and multiple } \\
\text { ankyrin repeat domains } 2 \text { (SHANK2), } \\
\text { transcript variant 1, mRNA } \\
\text { [NM_012309] }\end{array}$ \\
\hline CCDC81 & 0.004982437 & 3.2717588 & down & 1.533572 & down & 4.912844 & down & $\begin{array}{l}\text { Homo sapiens coiled-coil domain } \\
\text { containing } 81 \text { (CCDC81), mRNA } \\
\text { [NM_021827] }\end{array}$ \\
\hline CCL11 & 0.008992519 & 3.1781478 & down & 4.050988 & down & 1.002582 & up & $\begin{array}{l}\text { Homo sapiens chemokine (C-C motif) } \\
\text { ligand } 11 \text { (CCL11), mRNA [NM_002986] }\end{array}$ \\
\hline CO647386 & 0.020776557 & 3.1651435 & down & 1.030158 & down & 1.631509 & down & $\begin{array}{l}\text { ILLUMIGEN_MCQ_40418 Katze_MMPB2 } \\
\text { Macaca mulatta cDNA clone } \\
\text { IBIUW:21432 5' similar to Bases } 185 \text { to } \\
778 \text { highly similar to human CXCL2 } \\
\text { (Hs.75765), mRNA sequence } \\
\text { [CO647386] }\end{array}$ \\
\hline GPR98 & 0.024752488 & 3.1570897 & down & 1.10821 & down & 3.919889 & down & $\begin{array}{l}\text { Homo sapiens G protein-coupled } \\
\text { receptor } 98 \text { (GPR98), transcript variant } \\
\text { 1, mRNA [NM_032119] }\end{array}$ \\
\hline TMEM59L & $5.34 \mathrm{E}-04$ & 3.137047 & up & 1.57364 & up & 1.407988 & up & $\begin{array}{l}\text { Homo sapiens transmembrane protein } \\
\text { 59-like (TMEM59L), mRNA [NM_012109] }\end{array}$ \\
\hline UGT1A6 & 0.040070046 & 3.1353552 & down & 2.066639 & down & 1.399845 & down & $\begin{array}{l}\text { Homo sapiens UDP } \\
\text { glucuronosyltransferase } 1 \text { family, } \\
\text { polypeptide A6 (UGT1A6), transcript } \\
\text { variant 1, mRNA [NM_001072] }\end{array}$ \\
\hline KCNE2 & 7.02E-04 & 3.1135461 & up & 1.972823 & up & 1.170852 & down & $\begin{array}{l}\text { Homo sapiens potassium voltage-gated } \\
\text { channel, Isk-related family, member } 2 \\
\text { (KCNE2), mRNA [NM_172201] }\end{array}$ \\
\hline XR_012376 & 0.022554293 & 3.0699794 & down & 1.9303 & down & 1.439485 & down & $\begin{array}{l}\text { PREDICTED: Macaca mulatta } \\
\text { hypothetical protein LOC710335 } \\
\text { (LOC710335), mRNA [XR_012376] }\end{array}$ \\
\hline RXFP1 & 0.002097808 & 3.0400152 & up & 1.931833 & up & 1.276558 & up & $\begin{array}{l}\text { Homo sapiens relaxin/insulin-like family } \\
\text { peptide receptor } 1 \text { (RXFP1), mRNA } \\
\text { [NM_021634] }\end{array}$ \\
\hline ITGBL1 & 0.02861261 & 3.0041916 & down & 2.563332 & down & 1.243521 & down & $\begin{array}{l}\text { Homo sapiens integrin, beta-like } 1 \\
\text { (with EGF-like repeat domains) (ITGBL1), } \\
\text { mRNA [NM_004791] }\end{array}$ \\
\hline PASK & 0.03426426 & 2.995584 & up & 5.977056 & up & 19.17474 & up & $\begin{array}{l}\text { Homo sapiens PAS domain containing } \\
\text { serine/threonine kinase (PASK), mRNA } \\
\text { [NM_015148] }\end{array}$ \\
\hline DEFB1 & 0.004949556 & 2.9797235 & down & 1.065357 & up & 2.807533 & down & $\begin{array}{l}\text { Homo sapiens defensin, beta } 1 \text { (DEFB1), } \\
\text { mRNA [NM_005218] }\end{array}$ \\
\hline WDR8 & 0.004681234 & 2.9781044 & down & 5.68043 & down & 8.061375 & down & $\begin{array}{l}\text { Homo sapiens WD repeat domain } 8 \\
\text { (WDR8), mRNA [NM_017818] }\end{array}$ \\
\hline
\end{tabular}


Table $\mathbf{3}$ List of top $\mathbf{5 0}$ genes significantly differentially regulated in liver based on fold difference (t-test). (Continued)

\begin{tabular}{|c|c|c|c|c|c|c|c|c|}
\hline RIMS4 & 0.04112827 & 2.9677074 & up & 1.724443 & up & 1.024011 & down & $\begin{array}{l}\text { Homo sapiens regulating synaptic } \\
\text { membrane exocytosis } 4 \text { (RIMS4), mRNA } \\
\text { [NM_182970] }\end{array}$ \\
\hline PDGFRL & 0.011396675 & 2.9371088 & down & 1.21306 & down & 1.55284 & down & $\begin{array}{l}\text { Homo sapiens platelet-derived growth } \\
\text { factor receptor-like (PDGFRL), mRNA } \\
\text { [NM_006207] }\end{array}$ \\
\hline TNRC4 & 0.005930619 & 2.9251838 & up & 1.208589 & up & 1.396738 & up & $\begin{array}{l}\text { Homo sapiens trinucleotide repeat } \\
\text { containing } 4 \text { (TNRC4), mRNA } \\
\text { [NM_007185] }\end{array}$ \\
\hline UGT2B11 & 0.02518766 & 2.9193914 & down & 1.09908 & down & 2.958316 & down & $\begin{array}{l}\text { Homo sapiens UDP } \\
\text { glucuronosyltransferase } 2 \text { family, } \\
\text { polypeptide B11 (UGT2B11), mRNA } \\
\text { [NM_001073] }\end{array}$ \\
\hline FLT3LG & 0.029793594 & 2.8908129 & up & 1.037797 & down & 1.527226 & up & $\begin{array}{l}\text { Homo sapiens fms-related tyrosine } \\
\text { kinase } 3 \text { ligand (FLT3LG), mRNA } \\
\text { [NM_001459] }\end{array}$ \\
\hline IP6K3 & 0.03900314 & 2.8685477 & up & 1.471319 & up & 1.39455 & down & $\begin{array}{l}\text { Homo sapiens inositol hexaphosphate } \\
\text { kinase } 3 \text { (IHPK3), mRNA [NM_054111] }\end{array}$ \\
\hline ST6GALNAC1 & 0.03669531 & 2.8622296 & down & 1.408642 & down & 2.126189 & down & $\begin{array}{l}\text { Homo sapiens ST6 (alpha-N-acetyl- } \\
\text { neuraminyl-2,3-beta-galactosyl-1,3)-N- } \\
\text { acetylgalactosaminide alpha-2,6- } \\
\text { sialyltransferase } 1 \text { (ST6GALNAC1), mRNA } \\
\text { [NM_018414] }\end{array}$ \\
\hline EFNA4 & 0.007086268 & 2.843187 & down & 1.084758 & up & 2.766163 & down & $\begin{array}{l}\text { Homo sapiens ephrin-A4 (EFNA4), } \\
\text { transcript variant 1, mRNA } \\
\text { [NM_005227] }\end{array}$ \\
\hline MYST3 & 0.013409907 & 2.827006 & up & 3.302978 & up & 1.403819 & up & $\begin{array}{l}\text { Homo sapiens MYST histone } \\
\text { acetyltransferase (monocytic leukemia) } \\
3 \text { (MYST3), mRNA [NM_006766] }\end{array}$ \\
\hline XM_370715 & 0.001614059 & 2.7565975 & up & 1.561267 & up & 2.382949 & up & $\begin{array}{l}\text { PREDICTED: Homo sapiens similar to } \\
\text { hypothetical protein MGC48915 } \\
\text { (LOC387911), mRNA [XM_370715] }\end{array}$ \\
\hline NM_031436 & 0.035783853 & 2.6903787 & up & 1.740635 & up & 1.698687 & up & $\begin{array}{l}\text { Homo sapiens aldo-keto reductase } \\
\text { family 1, member C-like } 2 \text { (AKR1CL2), } \\
\text { mRNA. [NM_031436] }\end{array}$ \\
\hline
\end{tabular}

more than a 10 fold shift in expression levels. There are important implications to this observation. Historically, experimental and epidemiological focus has been on the extremes of birth weight (either small for gestational age or large for gestational age) and there has been little focus within the normal birth weight range continuum. What is evident from the present study is that relatively small changes in the birth phenotype may be associated with profound changes in molecular physiology. In turn this also suggests the presence of highly evolved processes by which the fetus can adjust its development in response to subtle cues from mother [29].

The Cynomolgus, as in the human, has monotocous pregnancies with haemochorial placentae; they have omnivorous diets and monogastric digestion. They also share with humans the same progressive history of the metabolic syndrome [17]. We have identified alterations in the levels and expression patterns of a number of genes involved in different metabolic processes including cellular lipid metabolism, cellular biosynthesis, cellular macromolecule synthesis, cellular nitrogen metabolism, cellular carbohydrate metabolism, cellular catabolism, nucleotide and nucleic acid metabolism, biological adhesion and development.Recently, transcriptional profiling in rats subjected to gestational under nutrition was performed in young adult male rats where 249 genes were shown to be differentially expressed in the liver [28]. We compared the genes which are significantly altered in our array with those identified in the rat array study and have identified twelve similar or closely related genes from those identified in the rat: Tribbles homolog 2 (Trib2); 3-hydroxyanthanillate dioxygenase (Haao), transmembrane serine protease 6 (Tmmprss6); Thioredoxin domain containing10 (Txndc10); tralation initiation factor 4A3 (Eifa3); Ribosomal protein L31 (Rpl31); Danse 1-like 2 (Dnase112); Quinolate phosphoribosyl transferase (Qprt); general transcription factor IIa 2 (Gtf2a3); General transcription factor II H 3 [28]. Only four of these genes (Trib2, Trip10, EIF4A3 and Dnase112) were altered in the same direction in the livers of LBW macaques as in the rat array. We have also compared our observations with those identified from LBW 
Table 4 Top 50 genes significantly differentially regulated in cord based on fold difference (t-test).

\begin{tabular}{|c|c|c|c|c|c|c|c|c|}
\hline $\begin{array}{l}\text { Gene } \\
\text { Symbol }\end{array}$ & $\begin{array}{l}2 \text { Way } \\
\text { ANOVA P } \\
\text { value }\end{array}$ & $\begin{array}{l}\text { Fold } \\
\text { Change in } \\
\text { cord, } \\
\text { Welch t- } \\
\text { test }\end{array}$ & $\begin{array}{l}\text { Regulation } \\
\text { in LBW }\end{array}$ & $\begin{array}{l}\text { Fold } \\
\text { change } \\
\text { skeletal } \\
\text { tissue, } \\
\text { Welch t- } \\
\text { test }\end{array}$ & $\begin{array}{l}\text { Regulation } \\
\text { in LBW }\end{array}$ & $\begin{array}{l}\text { Fold } \\
\text { change } \\
\text { in liver, }\end{array}$ & $\begin{array}{l}\text { Regulation } \\
\text { in LBW }\end{array}$ & Gene name \\
\hline ATP5F1 & 0.003504217 & 29.998667 & down & 1.850386 & down & 1.153583 & down & $\begin{array}{l}\text { Homo sapiens ATP synthase, } \mathrm{H}+ \\
\text { transporting, mitochondrial F0 complex, } \\
\text { subunit B1 (ATP5F1), nuclear gene } \\
\text { encoding mitochondrial protein, mRNA } \\
\text { [NM_001688] }\end{array}$ \\
\hline EHHADH & $3.25 \mathrm{E}-05$ & 29.713446 & down & 1.004504 & up & 1.027032 & down & $\begin{array}{l}\text { Homo sapiens enoyl-Coenzyme A, } \\
\text { hydratase/3-hydroxyacyl Coenzyme A } \\
\text { dehydrogenase (EHHADH), mRNA } \\
\text { [NM_001966] }\end{array}$ \\
\hline CNPY2 & $6.12 \mathrm{E}-05$ & 24.275322 & down & 2.033511 & down & 1.345912 & down & $\begin{array}{l}\text { Homo sapiens transmembrane protein } \\
4 \text { (TMEM4), mRNA [NM_014255] }\end{array}$ \\
\hline IMMP1L & 5.31E-04 & 21.21959 & down & 1.067236 & down & 1.052987 & up & $\begin{array}{l}\text { Homo sapiens IMP1 inner } \\
\text { mitochondrial membrane peptidase-like } \\
\text { (S. cerevisiae) (IMMP1L), mRNA } \\
\text { [NM_144981] }\end{array}$ \\
\hline GNL2 & 0.008845676 & 19.523186 & down & 1.389994 & down & 1.352022 & up & $\begin{array}{l}\text { Homo sapiens guanine nucleotide } \\
\text { binding protein-like } 2 \text { (nucleolar) } \\
\text { (GNL2), mRNA [NM_013285] }\end{array}$ \\
\hline HRSP12 & 0.010644738 & 19.35189 & down & 1.121147 & up & 1.013192 & up & $\begin{array}{l}\text { Homo sapiens heat-responsive protein } \\
12 \text { (HRSP12), mRNA [NM_005836] }\end{array}$ \\
\hline CN643639 & $2.57 \mathrm{E}-05$ & 19.177528 & down & 1.710693 & down & 1.132373 & up & $\begin{array}{l}\text { ILLUMIGEN_MCQ_8235 Katze_MMBR } \\
\text { Macaca mulatta cDNA clone IBIUW:3333 } \\
\text { 5' similar to Bases } 1 \text { to } 682 \text { highly } \\
\text { similar to human Unigene Hs.513885, } \\
\text { mRNA sequence [CN643639] }\end{array}$ \\
\hline PASK & 0.03426426 & 19.17474 & up & 5.977056 & up & 2.995584 & up & $\begin{array}{l}\text { Homo sapiens PAS domain containing } \\
\text { serine/threonine kinase (PASK), mRNA } \\
\text { [NM_015148] }\end{array}$ \\
\hline NDUFC1 & $1.93 \mathrm{E}-04$ & 18.786453 & down & 1.418954 & down & 1.095977 & up & $\begin{array}{l}\text { Homo sapiens NADH dehydrogenase } \\
\text { (ubiquinone) 1, subcomplex unknown, } \\
\text { 1,6 kDa (NDUFC1), mRNA [NM_002494] }\end{array}$ \\
\hline BNIP3L & 3.67E-05 & 18.46857 & down & 2.523903 & down & 1.123252 & down & $\begin{array}{l}\text { Homo sapiens BCL2/adenovirus E1B } 19 \\
\text { kDa interacting protein 3-like (BNIP3L), } \\
\text { mRNA [NM_004331] }\end{array}$ \\
\hline GALE & 0.004030123 & 18.304993 & down & 1.591229 & up & 1.378757 & down & $\begin{array}{l}\text { Homo sapiens UDP-galactose-4- } \\
\text { epimerase (GALE), transcript variant 1, } \\
\text { mRNA [NM_000403] }\end{array}$ \\
\hline XM_371837 & $2.06 \mathrm{E}-06$ & 18.251152 & down & 1.76245 & down & 1.15429 & down & $\begin{array}{l}\text { PREDICTED: Homo sapiens similar to } \\
\text { oxidoreductase UCPA (LOC389416), } \\
\text { mRNA [XM_371837] }\end{array}$ \\
\hline OSTCL & $9.90 \mathrm{E}-05$ & 17.57389 & down & 1.173702 & down & 1.075778 & down & $\begin{array}{l}\text { Homo sapiens similar to RIKEN cDNA } \\
\text { 2310008M10 (LOC202459), mRNA } \\
\text { [NM_145303] }\end{array}$ \\
\hline$\overline{\text { WDR75 }}$ & 7.83E-05 & 17.02899 & down & 2.353145 & down & 1.037028 & down & $\begin{array}{l}\text { Homo sapiens WD repeat domain } 75 \\
\text { (WDR75), mRNA [NM_032168] }\end{array}$ \\
\hline SMPDL3A & $1.25 \mathrm{E}-05$ & 16.127317 & down & 1.290077 & down & 1.780315 & down & $\begin{array}{l}\text { Homo sapiens sphingomyelin } \\
\text { phosphodiesterase, acid-like 3A } \\
\text { (SMPDL3A), mRNA [NM_006714] }\end{array}$ \\
\hline LIN7C & $6.29 \mathrm{E}-04$ & 15.929515 & down & 1.429568 & down & 1.006664 & down & $\begin{array}{l}\text { Homo sapiens lin-7 homolog C (C. } \\
\text { elegans) (LIN7C), mRNA [NM_018362] }\end{array}$ \\
\hline COX7B & 8.03E-06 & 15.9135065 & down & 1.283232 & down & 1.138854 & up & $\begin{array}{l}\text { Homo sapiens cytochrome c oxidase } \\
\text { subunit Vllb (COX7B), nuclear gene } \\
\text { encoding mitochondrial protein, mRNA } \\
\text { [NM_001866] }\end{array}$ \\
\hline
\end{tabular}


Table $\mathbf{4}$ Top $\mathbf{5 0}$ genes significantly differentially regulated in cord based on fold difference (t-test). (Continued)

\begin{tabular}{|c|c|c|c|c|c|c|c|c|}
\hline MRPL1 & $1.35 \mathrm{E}-06$ & 15.901582 & down & 1.776047 & down & 1.05264 & up & $\begin{array}{l}\text { Homo sapiens mitochondrial ribosomal } \\
\text { protein L1 (MRPL1), nuclear gene } \\
\text { encoding mitochondrial protein, mRNA } \\
\text { [NM_020236] }\end{array}$ \\
\hline NPM3 & $3.58 \mathrm{E}-04$ & 15.357531 & down & 1.39378 & down & 1.314134 & up & $\begin{array}{l}\text { Homo sapiens nucleophosmin/ } \\
\text { nucleoplasmin, } 3 \text { (NPM3), mRNA } \\
\text { [NM_006993] }\end{array}$ \\
\hline RNF126 & 4.43E-04 & 15.14725 & down & 1.165075 & down & 1.084156 & down & $\begin{array}{l}\text { Homo sapiens ring finger protein } 126 \\
\text { (RNF126), transcript variant 2, mRNA } \\
\text { [NM_194460] }\end{array}$ \\
\hline ATG4C & $1.86 \mathrm{E}-06$ & 14.422242 & down & 1.01449 & down & 1.571663 & down & $\begin{array}{l}\text { Homo sapiens ATG4 autophagy related } \\
4 \text { homolog C (S. cerevisiae) (ATG4C), } \\
\text { transcript variant 7, mRNA [NM_032852] }\end{array}$ \\
\hline ACMSD & $2.00 \mathrm{E}-04$ & 14.3137 & down & 1.121731 & up & 1.098467 & down & $\begin{array}{l}\text { Homo sapiens aminocarboxymuconate } \\
\text { semialdehyde decarboxylase (ACMSD), } \\
\text { mRNA [NM_138326] }\end{array}$ \\
\hline WASF3 & 0.0026955 & 14.211387 & down & 1.134297 & down & 1.574282 & up & $\begin{array}{l}\text { Homo sapiens WAS protein family, } \\
\text { member } 3 \text { (WASF3), mRNA } \\
\text { [NM_006646] }\end{array}$ \\
\hline$\overline{F 13 B}$ & $1.26 \mathrm{E}-05$ & 13.94526 & down & 1.052562 & down & 1.02993 & down & $\begin{array}{l}\text { Homo sapiens coagulation factor XIII, B } \\
\text { polypeptide (F13B), mRNA [NM_001994] }\end{array}$ \\
\hline HNRNPA1L2 & 0.007305239 & 13.879195 & down & 1.288451 & up & 1.062584 & down & $\begin{array}{l}\text { Homo sapiens heterogeneous nuclear } \\
\text { ribonucleoprotein A1-like (LOC144983), } \\
\text { transcript variant 1, mRNA } \\
\text { [NM_001011724] }\end{array}$ \\
\hline XR_011737 & 0.001940294 & 13.592515 & down & 1.736661 & down & 1.168041 & up & $\begin{array}{l}\text { PREDICTED: Macaca mulatta similar to } \\
\text { transcription factor B2, mitochondrial } \\
\text { (LOC710669), mRNA [XR_011737] }\end{array}$ \\
\hline $\mathrm{CP}$ & $1.42 \mathrm{E}-04$ & 13.285389 & down & 1.122256 & down & 1.274657 & down & $\begin{array}{l}\text { Homo sapiens ceruloplasmin } \\
\text { (ferroxidase) (CP), mRNA [NM_000096] }\end{array}$ \\
\hline$\overline{\text { TOLLIP }}$ & $1.59 \mathrm{E}-04$ & 12.683504 & down & 1.156986 & down & 1.00844 & down & $\begin{array}{l}\text { Homo sapiens toll interacting protein } \\
\text { (TOLLIP), mRNA [NM_019009] }\end{array}$ \\
\hline DARS & 3.99E-05 & 12.632657 & down & 3.152794 & down & 1.10567 & down & $\begin{array}{l}\text { Homo sapiens aspartyl-tRNA synthetase } \\
\text { (DARS), mRNA [NM_001349] }\end{array}$ \\
\hline$\overline{C K L F}$ & $4.24 \mathrm{E}-04$ & 12.476327 & down & 1.130294 & down & 1.064736 & down & $\begin{array}{l}\text { Homo sapiens chemokine-like factor } \\
\text { (CKLF), transcript variant 1, mRNA } \\
\text { [NM_016951] }\end{array}$ \\
\hline STT3B & $1.13 \mathrm{E}-04$ & 12.457355 & down & 2.027118 & down & 1.030927 & down & $\begin{array}{l}\text { Homo sapiens STT3, subunit of the } \\
\text { oligosaccharyltransferase complex, } \\
\text { homolog B (S. cerevisiae) (STT3B), } \\
\text { mRNA [NM_178862] }\end{array}$ \\
\hline$\overline{T X N D C 11}$ & $4.40 \mathrm{E}-05$ & 12.377014 & down & 1.525444 & down & 1.011564 & down & $\begin{array}{l}\text { Homo sapiens thioredoxin domain } \\
\text { containing } 11 \text { (TXNDC11), mRNA } \\
\text { [NM_015914] }\end{array}$ \\
\hline CR603105 & $9.80 \mathrm{E}-04$ & 12.209639 & down & 1.284419 & down & 1.155491 & down & $\begin{array}{l}\text { full-length cDNA clone CSODF006YN22 } \\
\text { of Fetal brain of Homo sapiens (human) } \\
\text { [CR603105] }\end{array}$ \\
\hline XR_010672 & 5.09E-05 & 11.634537 & down & 1.602301 & down & 1.059423 & up & $\begin{array}{l}\text { PREDICTED: Macaca mulatta similar to } \\
\text { Molybdenum cofactor synthesis protein } \\
2 \text { large subunit (Molybdopterin } \\
\text { synthase large subunit) (MPT synthase } \\
\text { large subunit) (MOCS2B) (MOCO1-B) } \\
\text { (LOC703049), mRNA [XR_010672] }\end{array}$ \\
\hline GDE1 & 0.03917646 & 11.536806 & down & 1.190901 & up & 1.20255 & up & $\begin{array}{l}\text { Homo sapiens membrane interacting } \\
\text { protein of RGS16 (MIR16), mRNA } \\
\text { [NM_016641] }\end{array}$ \\
\hline$\overline{\text { CFHR2 }}$ & 2.07E-04 & 11.37657 & down & 1.208862 & down & 1.032327 & down & $\begin{array}{l}\text { Homo sapiens complement factor } \mathrm{H} \text { - } \\
\text { related } 2 \text { (CFHR2), mRNA [NM_005666] }\end{array}$ \\
\hline RPL30 & 0.03067462 & 11.374878 & down & 1.173423 & up & 1.096937 & up & $\begin{array}{l}\text { Homo sapiens ribosomal protein L30 } \\
\text { (RPL30), mRNA [NM_000989] }\end{array}$ \\
\hline
\end{tabular}


Table $\mathbf{4}$ Top $\mathbf{5 0}$ genes significantly differentially regulated in cord based on fold difference (t-test). (Continued)

\begin{tabular}{|c|c|c|c|c|c|c|c|c|}
\hline XM_495885 & 0.002429009 & 11.322625 & down & 1.165255 & down & 1.156577 & down & $\begin{array}{l}\text { PREDICTED: Homo sapiens similar to } \\
\text { ribosomal protein S12 (LOC440055), } \\
\text { mRNA [XM_495885] }\end{array}$ \\
\hline NDUFB1 & $2.13 \mathrm{E}-04$ & 11.293429 & down & 1.404433 & down & 1.277028 & up & $\begin{array}{l}\text { Homo sapiens NADH dehydrogenase } \\
\text { (ubiquinone) } 1 \text { beta subcomplex, 1, } 7 \\
\text { kDa (NDUFB1), mRNA [NM_004545] }\end{array}$ \\
\hline NM_032807 & 2.89E-04 & 11.240869 & down & 1.075345 & down & 1.014724 & down & $\begin{array}{l}\text { Homo sapiens F-box protein, helicase, } \\
18 \text { (FBX018), transcript variant 1, mRNA. } \\
\text { [NM_032807] }\end{array}$ \\
\hline $\begin{array}{l}\text { CSGALNACT } \\
2\end{array}$ & $1.34 \mathrm{E}-05$ & 11.216295 & down & 1.714551 & down & 1.080183 & down & $\begin{array}{l}\text { Homo sapiens chondroitin sulfate } \\
\text { GalNACT-2 (GALNACT-2), mRNA } \\
\text { [NM_018590] }\end{array}$ \\
\hline NM_022333 & 0.002598488 & 10.94874 & down & 1.130622 & up & 1.014866 & down & $\begin{array}{l}\text { Homo sapiens TIA1 cytotoxic granule- } \\
\text { associated RNA binding protein-like } 1 \\
\text { (TIAL1), ranscript variant 2, mRNA } \\
\text { [NM_022333] }\end{array}$ \\
\hline NM_032807 & 0.001172931 & 10.342792 & down & 1.522541 & down & 1.139832 & down & $\begin{array}{l}\text { Homo sapiens F-box protein, helicase, } \\
18 \text { (FBX018), transcript variant 1, mRNA. } \\
\text { [NM_032807] }\end{array}$ \\
\hline AAMP & $2.62 \mathrm{E}-05$ & 10.171815 & down & 1.560637 & down & 1.085371 & down & $\begin{array}{l}\text { Homo sapiens angio-associated, } \\
\text { migratory cell protein (AAMP), mRNA } \\
\text { [NM_001087] }\end{array}$ \\
\hline ESF1 & $1.02 \mathrm{E}-07$ & 9.745275 & down & 1.620818 & down & 1.008674 & down & $\begin{array}{l}\text { Homo sapiens ESF1, nucleolar pre-rRNA } \\
\text { processing protein, homolog (S. } \\
\text { cerevisiae) (ESF1), mRNA [NM_016649] }\end{array}$ \\
\hline DOCK7 & 0.01799708 & 9.74066 & down & 1.174452 & up & 1.171709 & up & $\begin{array}{l}\text { Homo sapiens dedicator of cytokinesis } \\
7 \text { (DOCK7), mRNA [NM_033407] }\end{array}$ \\
\hline DDX3Y & $4.78 \mathrm{E}-06$ & 9.687978 & down & 1.356089 & down & 1.134329 & down & $\begin{array}{l}\text { Homo sapiens DEAD (Asp-Glu-Ala-Asp) } \\
\text { box polypeptide 3, Y-linked (DDX3Y), } \\
\text { mRNA [NM_004660] }\end{array}$ \\
\hline XIAP & $3.65 E-05$ & 9.587557 & down & 1.882389 & down & 1.280735 & up & $\begin{array}{l}\text { Homo sapiens baculoviral IAP repeat- } \\
\text { containing } 4 \text { (BIRC4), mRNA } \\
\text { [NM_001167] }\end{array}$ \\
\hline TRPC4AP & $9.51 \mathrm{E}-05$ & 9.4549885 & down & 1.340843 & down & 1.07043 & up & $\begin{array}{l}\text { Homo sapiens transient receptor } \\
\text { potential cation channel, subfamily C, } \\
\text { member } 4 \text { associated protein } \\
\text { (TRPC4AP), transcript variant 1, mRNA } \\
\text { [NM_015638] }\end{array}$ \\
\hline ADK & $1.63 \mathrm{E}-04$ & 9.386349 & down & 5.639505 & down & 1.368648 & down & $\begin{array}{l}\text { Homo sapiens adenosine kinase (ADK), } \\
\text { transcript variant ADK-short, mRNA } \\
\text { [NM_001123] }\end{array}$ \\
\hline $\begin{array}{l}\text { NM_0010022 } \\
92\end{array}$ & $3.92 \mathrm{E}-04$ & 9.258961 & down & 1.016391 & up & 1.220083 & down & $\begin{array}{l}\text { Homo sapiens chromosome } 1 \text { open } \\
\text { reading frame } 139 \text { (C1orf139), transcript } \\
\text { variant 2, mRNA. [NM_001002292] }\end{array}$ \\
\hline
\end{tabular}

term placentas by McCarthy and colleagues [30] and found similarities in expression changes in the genes Procollagen-lysine, 2-oxoglutarate 5-dioygense (PLOD2); Soluble interleukin-1 receptor accessory protein (IL1RAP); Solute carrier family 2 (facilitated glucose transporter) member3 (SLC2A3); Myosin V1 (MYH6); Ribosomal protein S6(RPS6) and Latexin (LXN). The Tribbles homolog 2 (Trib2) is also increased in the LBW infants and suggests another possible way in way insulin/IGF-1 signalling might be impaired during development. Tribbles belongs to a family of kinase-like proteins and are reported to be negative regulators of Akt, the principle target of insulin signaling [31,32].
Studies using animal models such as rodents to understand the developmental origins of metabolic diseases have shown that epigenetic changes in genes correlates with expression changes including metabolic enzymes such as PEPCK, transcriptional factors such as PPAR $\alpha$ which regulate fat metabolism and factors associated with insulin action (e.g. PI3 kinase, PKC- $\zeta$ ), the key regulatory genes which are responsible for bringing these changes are not known [15,33]. One aim in our study was to identify whether there were shifts within the expression of key early regulators and from the array we have identified one such key regulatory gene the PAS Kinase (PASK), an evolutionarily conserved PAS domain containing serine/threonine kinase whose expression is 
Table 5 Gene ontology classification to group genes using Genespring ver10 (Agilent Tech, Santa Clara) of similar functional families.

\begin{tabular}{|c|c|c|c|c|c|c|}
\hline \multirow[b]{3}{*}{ Cellular lipid metabolic process } & \multicolumn{2}{|c|}{ Skeletal muscle } & \multicolumn{2}{|l|}{ Liver } & \multicolumn{2}{|l|}{ Cord } \\
\hline & $\begin{array}{l}\text { Up } \\
\text { regulated }\end{array}$ & $\begin{array}{l}\text { Down } \\
\text { regulated }\end{array}$ & $\begin{array}{l}\text { Up } \\
\text { regulated }\end{array}$ & $\begin{array}{l}\text { Down } \\
\text { regulated }\end{array}$ & $\begin{array}{l}\text { Up } \\
\text { regulated }\end{array}$ & $\begin{array}{l}\text { Down } \\
\text { regulated }\end{array}$ \\
\hline & 15 & 6 & 4 & 4 & 13 & 11 \\
\hline Cellular biosynthesis process & 8 & 14 & 6 & 4 & 16 & 40 \\
\hline Cellular macromolecule synthesis & 21 & 32 & 19 & 14 & 45 & 63 \\
\hline Cellular nitrogen metabolic process & 4 & 1 & 4 & 0 & 7 & 1 \\
\hline Cellular carbohydrate metabolic process & 2 & 0 & 0 & 0 & 2 & 1 \\
\hline Cellular catabolic process & 1 & 2 & 0 & 0 & 2 & 1 \\
\hline $\begin{array}{l}\text { Nucleobase, Nucleoside, nucleotide and nucleic acid } \\
\text { metabolic process }\end{array}$ & 19 & 17 & 15 & 4 & 66 & 43 \\
\hline Other cellular metabolic process & 3 & 2 & 1 & 3 & 3 & 15 \\
\hline Other metabolic process & 5 & 7 & 5 & 2 & 9 & 11 \\
\hline Transport & 30 & 17 & 21 & 14 & 39 & 26 \\
\hline Regulation of molecular functions & 4 & 2 & 1 & 1 & 12 & 8 \\
\hline Biological adhesion & 6 & 8 & 4 & 5 & 8 & 10 \\
\hline Developmental process & 19 & 11 & 7 & 4 & 20 & 16 \\
\hline Other biological process & 38 & 38 & 25 & 19 & 65 & 59 \\
\hline
\end{tabular}

altered as a result of adverse early developmental conditions. PAS domains are evolutionarily conserved and appear from archaea, bacteria to eukaryotes and are present in many signaling proteins where they act as signal sensor domain [34]. The PASK gene, whereby expression was up regulated in the LBW animals, has been shown to be a metabolic sensor based on mice knockout studies; mice lacking PASK are resistant to high-fat induced obesity, hepatic steatosis and are resistant to insulin [35].

\section{Conclusions}

In summary, this paper has identified significant variation in gene expression in multiple tissues in primate newborns of different growth trajectories but within the normative range of birth size. Further detailed analyses

Table 6 Verification of seven genes from the microarray using Real-time RT-PCR analysis in skeletal muscle.

\begin{tabular}{|c|c|c|c|c|}
\hline Gene Symbol and description & $\begin{array}{l}2 \text { way ANOVA p-value } \\
\text { (Birth weight) }\end{array}$ & $\begin{array}{l}\text { Microarray Fold } \\
\text { change (t-Test) }\end{array}$ & $\begin{array}{l}\text { Regulation in } \\
\text { LBW }\end{array}$ & $\begin{array}{l}\text { qPCR-Fold } \\
\text { Change }\end{array}$ \\
\hline XM_116936 & 0.017913306 & 10.054285 & Up regulated & \\
\hline $\begin{array}{l}\text { PREDICTED: Homo sapiens similar to RIKEN cDNA } \\
\text { 4832428D23 gene }\end{array}$ & & & & 4.780893 \\
\hline PASK: & 0.03426426 & 5.977056 & Up regulated & \\
\hline $\begin{array}{l}\text { Homo sapiens PAS domain containing serine/threonine } \\
\text { kinase }\end{array}$ & & & & 14.55481 \\
\hline ADK: & $1.63 \mathrm{E}-04$ & -5.639505 & Down regulated & \\
\hline $\begin{array}{l}\text { Homo sapiens adenosine kinase, (transcript variant ADK- } \\
\text { short) }\end{array}$ & & & & -3.57235 \\
\hline \multicolumn{5}{|l|}{ ELMOD1: } \\
\hline $\begin{array}{l}\text { Homo sapiens ELMO/CED-12 domain containing } 1 . \\
\text { SIX1: }\end{array}$ & 0.011425177 & -1.7373136 & Down regulated & -1.71015 \\
\hline $\begin{array}{l}\text { Homo sapiens sine oculis homeobox homolog } 1 \\
\text { (Drosophila). }\end{array}$ & 0.045728132 & 1.1253903 & $\begin{array}{l}\text { Up in low birth } \\
\text { weight }\end{array}$ & 1.246574 \\
\hline \multicolumn{5}{|l|}{ RBL1: } \\
\hline $\begin{array}{l}\text { Homo sapiens retinoblastoma-like } 1 \text { (p107), (transcript } \\
\text { variant 1) }\end{array}$ & 0.011705314 & 1.5320477 & Up regulated & 3.023726 \\
\hline \multicolumn{5}{|l|}{ SLC12A9: } \\
\hline $\begin{array}{l}\text { Homo sapiens solute carrier family } 12 \text { (potassium/chloride } \\
\text { transporters), member } 9 .\end{array}$ & $1.31 \mathrm{E}-05$ & 1.3670695 & Up regulated & 1.694303 \\
\hline
\end{tabular}


may improve our understanding of how alterations in such genes due to adverse early life environment predisposes towards metabolic syndrome. These data give strength to the hypothesis that developmental plasticity operating within the normative range of birth weights can influence metabolic and other physiological systems in a way that might have later health consequences. It emphasizes that the concept of developmental programming need not involve pathological changes in growth trajectories to have molecular and presumably functional consequences.

\section{Additional material}

Additional file 1: Genes which were differentially regulated between the ABW and LBW groups classified based on GO terms.

Genes with $\mathrm{a} \geq 1.5$ fold change at least in one tissue with a $p$ value of $\geq$ 0.5 identified from the array with the GO terms

\section{Acknowledgements}

BSE, RK, PDG, KC, SM are supported by Agency for Science, Technology and research (Singapore). PDG, DMS, MHV are funded by the National Research Centre for Growth and Development, University of Auckland (New Zealand)

\section{Author details}

${ }^{1}$ Growth, Development and Metabolism Programme, Singapore Institute for Clinical Sciences, Brenner Centre for Molecular Medicine, 30 Medical Drive, Singapore. ${ }^{2}$ Liggins Institute and the National Research Centre for Growth and Development, The University of Auckland, Private Bag 92019, Auckland 1142, New Zealand. ${ }^{3}$ Division of Molecular Genetics \& Cell Biology, School of Biological Sciences, Nanyang Technological University, Singapore, Singapore. ${ }^{4}$ Department of Anatomy, Faculty of medicine and Health Sciences, UAE University, Tawam Medical Campus, PO BOX 17666, Al ain, UAE.

\section{Authors' contributions}

BSE, RK and PDG conceived the study. KC, DMS and MHV coordinated and collected the animal samples. BSE and SM undertook the molecular biology. BSE and PDG wrote the manuscript. BSE, KC, DMS, SM, MHV, RK and PDG reviewed/edited manuscript. All authors read and approved the final manuscript.

\section{Competing interests}

The authors declare that they have no competing interests.

Received: 22 February 2011 Accepted: 16 October 2011

Published: 16 October 2011

\section{References}

1. Barker DJ, Winter PD, Osmond C, Margetts B, Simmonds SJ: Weight in infancy and death from ischaemic heart disease. Lancet 1989, 2(8663):577-80.

2. Barker DJP: The fetal and infant origins of adult disease, London. British Medical Journal Publishing 1993, 1-343.

3. Barker DJ, Gluckman PD, Godfrey KM, Harding JE, Owens JA, Robinson JS: Fetal nutrition and cardiovascular disease in adult life. Lancet 1993, 341(8850):938-41.

4. Phillips P, Wilson D, Taylor A, Esterman A, Wakefield M: Cardiovascular risk factors in South Australians with diabetes. Aust J Public Health 1994, 18(4):445-9.

5. Curhan GC, Chertow GM, Willett WC, Spiegelman D, Colditz GA, Manson JE, Speizer FE, Stampfer MJ: Birth weight and adult hypertension and obesity in women. Circulation 1996, 94(6):1310-5.
6. Curhan GC, Willett WC, Rimm EB, Spiegelman D, Ascherio AL, Stampfer MJ: Birth weight and adult hypertension, diabetes mellitus, and obesity in US men. Circulation 1996, 94(12):3246-50.

7. Burdge GC, Lillycrop KA: Nutrition, epigenetics, and developmental plasticity: implications for understanding human disease. Annu Rev Nutr 2010, 30:315-39

8. Gluckman PD, Hanson MA, Bateson P, Beedle AS, Law CM, Bhutta ZA, Anokhin KV, Bougnères $P$, Chandak GR, Dasgupta $P$, Smith GD, Ellison PT, Forrester TE, Gilbert SF, Jablonka E, Kaplan H, Prentice AM, Simpson SJ, Uauy R, West-Eberhard MJ: Towards a new developmental synthesis: adaptive developmental plasticity and human disease. Lancet 2009, 373(9675):1654-7

9. Gluckman PD, Hanson MA: Living with the past: evolution, development, and patterns of disease. Science 2004, 305(5691):1733-6.

10. Gluckman PD, Hanson MA, Beedle AS: Early life events and their consequences for later disease: a life history and evolutionary perspective. Am J Hum Biol 2007, 19(1):1-19.

11. Hales CN, Barker DJ: The thrifty phenotype hypothesis. Br Med Bull 2001, 60:5-20.

12. Gluckman PD, Hanson MA, Cooper C, Thornburg KL: Effect of in utero and early-life conditions on adult health and disease. N Engl J Med 2008, 359(1):61-73.

13. Burdge GC, Hanson MA, Slater-Jefferies JL, Lillycrop KA: Epigenetic regulation of transcription: a mechanism for inducing variations in phenotype (fetal programming) by differences in nutrition during early life? Br J Nutr 2007, 97(6):1036-46

14. Lillycrop KA, Slater-Jefferies JL, Hanson MA, Godfrey KM, Jackson AA Burdge GC: Induction of altered epigenetic regulation of the hepatic glucocorticoid receptor in the offspring of rats fed a protein-restricted diet during pregnancy suggests that reduced DNA methyltransferase-1 expression is involved in impaired DNA methylation and changes in histone modifications. Br J Nutr 2007, 97:1064-73.

15. Vickers MH, Gluckman PD, Coveny AH, Hofman PL, Cutfield WS, Gertler A, Breier $\mathrm{BH}$, Harris M: Neonatal leptin treatment reverses developmental programming. Endocrinology 2005, 146(10):4211-6.

16. Vickers $M H$, Gluckman PD, Coveny $\mathrm{AH}$, Hofman $\mathrm{PL}$, Cutfield WS, Gertler A, Breier $\mathrm{BH}$, Harris $\mathrm{M}$ : The effect of neonatal leptin treatment on postnatal weight gain in male rats is dependent on maternal nutritional status during pregnancy. Endocrinology 2008, 149(4):1906-13.

17. Wagner JE, Kavanagh K, Ward GM, Auerbach BJ, Harwood HJ Jr, Kaplan JR: Old world nonhuman primate models of type 2 diabetes mellitus. ILAR J 2006, 47(3):259-71

18. Tarantal AF, HendrickX AG: Charecterization of prenatal growth and development in the Crab-eating macaque (Macaca fasicularis) by ultrasound. The Anatomical record 1988, 222:177-184.

19. Rozen S, Skaletsky H: Primer3 on the WWW for general users and for biologist programmers. Methods mol Biol 2000, 132:365-386.

20. Schmittgen TD, Livak KJ: Analyzing real-time PCR data by the comparative C(T) method. Nat Protoc 2008, 3(6):1101-8.

21. Gluckman PD, Hanson MA: Maternal constraint of fetal growth and its consequences. Semin Fetal Neonatal Med 2004, 9(5):419-25.

22. Godfrey KM, Gluckman PD, Hanson MA: Developmental origins of metabolic disease: life course and intergenerational perspectives. Trends Endocrinol Metab 2010, 21(4):199-205.

23. Vickers $M H$, Breier BH, Cutfield WS, Hofman PL, Gluckman PD: Fetal origins of hyperphagia, obesity, and hypertension and postnatal amplification by hypercaloric nutrition. Am J Physiol Endocrinol Metab 2000, 279(1):E83-7.

24. Vickers $M H$, Reddy S, Ikenasio BA, Breier BH: Dysregulation of the adipoinsular axis-a mechanism for the pathogenesis of hyperleptinemia and adipogenic diabetes induced by fetal programming. J Endocrinol 2001, 170(2):323-32.

25. Vickers MH, Breier BH, McCarthy D, Gluckman PD: Sedentary behavior during postnatal life is determined by the prenatal environment and exacerbated by postnatal hypercaloric nutrition. Am J Physiol Regul Integr Comp Physiol 2003, 285(1):R271-3.

26. Lillycrop KA, Phillips ES, Jackson AA, Hanson MA, Burdge GC: Dietary protein restriction of pregnant rats induces and folic acid supplementation prevents epigenetic modification of hepatic gene expression in the offspring. J Nutr 2005, 135(6):1382-6.

27. Lillycrop KA, Rodford J, Garratt ES, Slater-Jefferies JL, Godfrey KM, Gluckman PD, Hanson MA, Burdge GC: Maternal protein restriction with 
or without folic acid supplementation during pregnancy alters the hepatic transcriptome in adult male rats. Br J Nutr 2010, 103(12):1711-9.

28. Morris TJ, Vickers M, Gluckman P, Gilmour S, Affara N: Transcriptional profiling of rats subjected to gestational undernourishment: implications for the developmental variations in metabolic traits. PLoS One 2009, 4(9): e7271.

29. Gluckman PD, Hanson MA, Morton SM, Pinal CS: Life-long echoes-a critical analysis of the developmental origins of adult disease model. Biol Neonate 2005, 87(2):127-39.

30. McCarthy C, Cotter FE, McElwaine S, Twomey A, Mooney EE, Ryan F, Vaughan J: Altered gene expression patterns in intrauterine growth restriction: potential role of hypoxia. Am J Obstet Gynecol 2007, 196(1):70. e1-6.

31. Du K, Herzig S, Kulkarni RN, Montminy M: TRB3: a tribbles homolog that inhibits Akt/PKB activation by insulin in liver. Science 2003, 300(5625):1574-7.

32. Hegedus Z, Czibula A, Kiss-Toth E: Tribbles: a family of kinase-like proteins with potent signalling regulatory function. Cell Signal 2007, 19(2):238-50.

33. Godfrey KM, Lillycrop KA, Burdge GC, Gluckman PD, Hanson MA: Epigenetic mechanisms and the mismatch concept of the developmental origins of health and disease. Pediatr Res 2007, 61:5R-10R.

34. Rutter J, Michnoff CH, Harper SM, Gardner KH, McKnight SL: PAS kinase: an evolutionarily conserved PAS domain-regulated serine/threonine kinase. Proc Natl Acad Sci USA 2001, 98(16):8991-6.

35. Hao HX, Cardon CM, Swiatek W, Cooksey RC, Smith TL, Wilde J, Boudina S, Abel ED, McClain DA, Rutter J: PAS kinase is required for normal cellular energy balance. Proc Natl Acad Sci USA 2007, 104(39):15466-71.

doi:10.1186/1471-2164-12-509

Cite this article as: Emerald et al.: Gene expression profiling in the Cynomolgus macaque Macaca fascicularis shows variation within the normal birth range. BMC Genomics 2011 12:509.

\section{Submit your next manuscript to BioMed Central and take full advantage of:}

- Convenient online submission

- Thorough peer review

- No space constraints or color figure charges

- Immediate publication on acceptance

- Inclusion in PubMed, CAS, Scopus and Google Scholar

- Research which is freely available for redistribution

Submit your manuscript at www.biomedcentral.com/submit 